East African Medical Journal Vol. 86 No. 3 March 2009

LAPAROSCOPIC MANAGEMENT OF UTERINE PERFORATION: REPORT OF THREE CASES

R. B Parkar, MBBS, MMed, FAGE, Dip. Lap. Surg., Consultant Obstetrician and Gynaecologist, P. O. Box 520, Sarit Centre, 00604, Nairobi, Kenya and Y. Patel, MBBS, MD, Consultant Obstetrician and Gynaecologist, P.O. Box 38121- 00623, Nairobi, Kenya

Request for reprints to: Dr. R. B. Parkar, P.O. Box 520, Sarit Centre 00600, Nairobi, Kenya

\title{
LAPAROSCOPIC MANAGEMENT OF UTERINE PERFORATION: REPORT OF THREE CASES
}

\author{
R. B. PARKAR and Y. PATEL
}

\section{SUMMARY}

\begin{abstract}
We present three cases of uterine perforation which were managed laparoscopically at the Aga Khan University Hospital Nairobi, between January and December 2008. Our objective was to determine the outcomes of uterine perforations and to create awareness on the availability of the laparoscopic management at such complications and to recommend the procedure as a suitable option to laparotomy.
\end{abstract}

\section{INTRODUCTION}

Termination of pregnancy and hysteroscopy are the most commonly performed gynaecological procedures, the safety of which is of global concern. Uterine perforation is one of their commonest complications. Traditionally, most of these complications weremanaged by laparotomy, however, with the increasing availability of operative laparoscopy, it's becoming possible to manage these cases laparoscopically. We present three cases of laparoscopic management of uterine perforation resulting from termination of pregnancy and hysteroscopy as opposed to either laparotomy or diagnostic laparoscopy followed by laparotomy.

Case 1: A 30 year old para $1+0$ presented, one month after having had termination of pregnancy at nine weeks gestation, with a history of lower abdominal pain and heavy irregular $\mathrm{p} v$ bleeding. She had been admitted and investigated and treated 10 days prior at another hospital. At this admission the uterine perforation was not detected.

During her second admission she was haemodynamically stable, abdomen was tender, bowel sounds heard. On speculum examination, there were clots in the posterior fornix, and a vaginal examination revealed a bulky uterus with tender adnexia. Her blood investigations were normal, the pregnancy test was negative and a pelvic ultrasound was non conclusive. Serum BHCG was negative and she consented to a diagnostic hysteroscopy and laparoscopy.

At diagnostic hysteroscopy adequate distension was obtained and the view was obscure. At this point a uterine perforation was suspected. She was repositioned and at laparoscopy two perforations were noted, one at the right cornu and one in the lower uterine segment The lower uterine segment was nectrotic and repair proved difficult hence a total laparoscopic hysterectomy was undertaken successfully. Her post operative recovery was unremarkabie and she was discharged on day two. The patient was reviewed six weeks postoperatively and was in satisfactory condition.

Case 2: A 25 year old para $0+0$ was under a diagnostic hysteroscopy and laparoscopy for primary infertility.

At hysteroscopy the view was obscure, and adequate distension was not obtained. On withdrawing the hysteroscope a fundal perforation was noted. She was in stable condition, was repositioned and a laparoscopy performed, which revealed a 0.5 to $1.0 \mathrm{~cm}$ perforation at the fundus. The bowl and omentum were not traumatised. The bleeding was minimal. The defect was sutured laparoscopically in two layers using intracorporeal sutures. The rest of the procedure was uneventful. Her post operative recovery was satisfactory, she was subsequently discharged on day two, and reviewed after six weeks.

Case 3: A 32 year old para $0+2$, who had had two previous terminations of pregnancy, was referred with a one month history of amenorrhoea and a diagnosis of Ashermanns syndrome on hysterosalpingogram. At presentation she was in stable condition. Abdominal examination revealed a non distended, non tender abdomen. Abdominal x-rays were normal. All her other investigations were normal.

She was prepared for hysteroscopic synechiolysis. At hysteroscopy dense intrauterine 
adhesions were encountered. These were resected using the Bertocchi sharp scissors. The fundus was visualised and the right ostia was clearly seen. The left appeared obscure. At this stage a silicon catheter, size 12 , was inserted into the uterine cavity to maintain patency. A perforation was not suspected. She was repositioned and at laparoscopy a $2-3 \mathrm{~cm}$ fundal perforation with the catheter bulb, protruding through was noted. The bleeding was minimal and intra abdominal fluid was minimal. The catheter was removed and the defect was sutured laparoscopically using intracorporeal sutures. She removed well and was discharged in satisfactory condition.

\section{DISCUSSION}

Termination of pregnancy and hysteroscopy are commonest gynaecological procedures performed (1). Theincidence of uterine perforation during first trimester termination of pregnancy has been estimated at $0.8-6.4 / 1000$ procedures (1). General anaesthesia, advanced age and parity have been associated with increased incidence of this complication (2). Uterine retroversion does not significantly contribute to perforation (3). It has been suggested that most cases of uterine perforation go unnoticed. In studies where direct visualisation was employed at the time of procedure, the incidence was estimated at $30 / 1000$ (4).

A conservative approach to the management of uterine perforations has been described by several authors, with surgical intervention necessary in cases of increasing pain, haemodynamic instability and evidence of intra abdominal viscus perforation or protrusion of abdominal content through the cervix ( 5 ). Others advocate that laparoscopy should be used in all cases, where uterine perforation is suspected (6), however there is sparse literature on laparoscopic repair of uterine perforations. Nathanson (7) in a series of 24 perforations, managed 13 patients conservatively and in ten performed laparotomy to effect uterine repair. In a series by Freiman and Wulff (18), four patients needed laparotomy for insertion of sutures, though three of these needed other therapeutic procedures. In a more recent series, Goldchmit and colleagues performed laparotomy in six patients to insert uterine sutures with no other treatment carried out. Puharic et at (10) managed uterine perforations laparoscopicaly with low voltage endodiathermy to stop bleeding without insertion of sutures, this may lead to weakness of the uterine wall, which may result in uterine perforation in future pregnancy. In this series all the perforations were managed laparoscopically. In the cases presented, in case
1 and 2, the perforation was obviously caused by the instruments. However, in case 3 , it is possible that the perforation may have been caused by the foleys catheter balloon, since adequate distention of the uterine cavity was maintained until withdrawal of the hysteroscope.

The literature is scarce on the laparoscopic repair of uterine perforation with application of intracorporeal sutures. This method of repair has the advantage of preventing a laparotomy in cases where haemostasis cannot be achieved with diathermy and ensuring integrity of the uterine wall. There is an added psychological advantage to the patient with regard to hospital stay (11).

Laparoscopic management of uterine perforation in haemodynamically stable patients is feasible, as illustrated in these case reports. It also has the advantage of shorter hospital stay, earlier return to normal activities and all other advantaged of laparoscopic surgery.

In conclusion, there is a reported increase in the number of surgical termination of pregnancy performed annually. For women requiring intervention as a result of uterine perforation, laparoscopy is viable intervention not only for diagnosis leading to laparotomy, but also for treatment.

\section{ACKNOWLEDGEMENTS}

To the patients and theatre staff of the Aga Khan University Hospital, Nairobi.

\section{REFERENCES}

1. Ganesh, A., Heulwen, M., Leslie, P. and Regina, F. A randomised trial comparing surgical termination of pregnancy with or without continuous ultrasound. Eur. J. Obstet. Gynecol. Reprod. Biol. 2004; 114: 69 - 74.

2. Kaali, S. G., Szigetvari, 1. A. and Bartfai, G. S. The frequency and management of uterine perforations during $1^{\text {st }}$ trimester abortions Am. J. Obstet. Gynecol. 1989; 161: 406 - 408.

3. Kumar, P. and Rao, P. Laparoscopy as a diagnostic and therapeutic technique in uterine perforations during $1^{\text {st }}$ trimester abortions. Asia Ocenia. J. Obstet. Gynecol. 1998; 14: 55 - 59.

4. White, M. K., Ory, H.W. and Goldenberg, L. A. A case control study of uterine perforations documented at laparoscopy. Am. J. Obstet Gynaecol. 1977; 129: 623.

5. Lindell, G. and Flam, F., Management of uterine perforations in connection with legal abortion. Acta. Obstect. Gynecol. Scand. 1995; 74: 373 - 375.

6. Lauerseen, N. H. and Bimbaum, S. Laparoscopy as a diagnostic and therapeutic technique in uterine perforations during first trimester abortions. Am. J. Obstet. Gynecol. 1977; 117: 522 - 526.

7. Nathanson, B. N. Management of uterine perforation suffered at elective abortion. Am. J. Obstet. Gynaecol. 1972; 114: 1054 - 1059. 
8. Feiman, S. M. and Wulff, G. J. Jr. Management of uterine perforation following elective abortion. Obstet. Gynaecol. 1977; 50: 647 - 650.

9. Goldchmit, R., Yaron, Z., Elchalal, U., Matzkel, A. and Dgani, R. Management of uterine perforation complicating first trimester termination of pregnancy. Isr. J. Med. Sci. 1995; 31: 232 - 234.
10. Puharic, I. Laparoscopy in the treatment of uterine perforation in induced abortions. Jugosl. Ginekol. Perinatol. 1990; 30: 121 - 125.

11. Mustafa,M.S. and Gurab,S.Endoscopicmanagement of bleeding uterine perforation occurring during evacuation of retained products of conception. Int J. Gynaecol. Obstet. 1995; 49: 71 - 72. 